\title{
Integrated communicative method as form of cooperation between teacher and student (from work experience)
}

\author{
A.A. Isakova \\ Industrial University of Tyumen \\ Tyumen Industrial University \\ Tyumen, Russia \\ IsakovaAA@yandex.ru
}

\begin{abstract}
This article is devoted to the problem of pedagogical methods in teaching a foreign language. The author describes the Russian traditional educational system and different teaching methods. The communicative method based on the author's own teaching experience is analyzed.
\end{abstract}

Keyword-foreign language, methodology, communicative method, teacher, student, linguistic identity.

\section{INTRODUCTION}

By the epigraph to this article, it is possible to identify A. Saint-Exupéry's words "The greatest luxury on earth is the luxury of human communication" [1]. The task of the teacher is not only to teach some lexical / grammatical norms of a foreign language, but also to develop a "foreign language" linguistic consciousness. It means that the teacher has to present methodically reasonably data on the culture of the country of the learned language and also to teach to understand the "foreign-language" linguistic personality, and hence, to understand one's own linguistic identity. It should be in an available to the pupil form.

The search for an answer to the traditional didactic question «How to teach?" leads us to the category of teaching methods. A method is a core of an educational process, a link between the designed purpose and the end result [2]. It is a huge variety of methods of teaching foreign languages, and the teacher will take only one of them as a basis. However, there is no doubt that the linguistic component of the methods of teaching foreign languages is so strong that it inevitably leads to various transformations in the language personality.

In this regard, the mentality becomes marginal. It is like the mentality of the diaspora [3] which forces us to pay closer attention to those internal processes in the language personality. Economic globalization and political consolidation lead to the critical analysis of the traditional system of foreign-language education and development of other conceptual approaches in modern society [4]. The support not only responds to the change of paradigms in the humanities, to data of cultural linguistics, but also assumes broader coverage of the studied problems which integrate achievements of various humanitarian scientific disciplines and different linguistic areas such as the functional direction, anthropolinguistics, the theory of speech genres, etc. [5].

At the present stage of the development of the society, specialists knowing several foreign languages are required. So the existing traditional methods have lost their relevance, and it is necessary to create a new theoretical and practical basis for more effective learning of a foreign language. This basis can be created using achievements in related sciences. Moreover, the situation of intensive globalization is interesting for the linguistic personality and transformations in the process of learning a foreign language.

There is a linguistic modeling of the language personality in a situation of a profound learning of a foreign language. There is also embedding of one language picture of the world into another.

The perspective and relevance of the following research are predetermined by the interest of modern linguistics in a problem "language and culture, language and the personality". The variety of the developing linguistic and cross-disciplinary approaches of the concept "language and culture" is one of key problems in linguistics of the end of the XX and the beginning of the XXI centuries. The author should pay attention to this problem too. Now Linguistic modeling is extremely demanded due to its explanatory power and the properties of language. So the construction of the evolution model of the language personality is promising and relevant in the process of teaching a foreign language.

The Russian educational system undergoes a number of changes in the conditions of the world integration processes. One of the main objectives of improvement of quality education is search for the methods and forms of the organization of the educational process giving the chance to provide its maximum efficiency.

It is known that the purpose of education is formation of certain qualities of the competitive personality and obtaining concrete qualities and skills. The purposes of the higher technical education find the concrete embodiment in 
vocational training of students. These purposes are concretized for individual disciplines, in this case: in the preparation of competitive specialists in the field of knowledge of foreign languages in the modern market of educational services, which requires the transformation of the teaching process and the control of knowledge of such discipline as a "foreign language".

The history of the methodology of teaching foreign languages knows numerous and diverse attempts to find the most rational method of teaching foreign languages. However, the question of the most effective method is still open in a foreign language teaching of all types of speech activity.

The basic principles of the new linguistic paradigm are cognitive, anthropocentric and functional (a communicative and pragmatic approach to verbal communication). These three principles do not oppose each other but they are closely interrelated. The main participant of communicative interaction is a linguistic personality at all levels of speech. "Cognitive, personal (individual-linguistic) and functional, communicative-pragmatic components form interactive levels of the linguistic consciousness of the individual" [6].

Now linguists have faced the person. "All this demonstrates the major methodological shift which was outlined in modern linguistics - about transition from linguistics immanent to linguistics anthropological" [7]. A language becomes the uniting beginning for so different areas of knowledge as philosophy, psychology, sociology and many others [8]. "The anthropological paradigm of studying a language is guided by comprehension of the language in close connection with life of the person, with human consciousness, thinking, culture, subject and practical and spiritual activity. The central methodological task is an explicit inclusion in ontology of the language. It allows explaining a uniform methodological basis of the most important moments of the language. They are nature, functional mission, formation, the general principles of the internal organization" [9].

Studying the interaction of languages by a certain party is connected with sociological studying of interaction of the nations. It is obvious that developments and rapprochements of the nations cannot but influence language development. The nature of interaction of their languages also depends on the nature of relationship of the people. The language occupies a special place in the process of ethno-national consolidation [10]. It ensures the naturalness of this process, coding it at the level of both consciousness and sub-consciousness. Each culture is endowed with certain basic characteristics that can be passed on to the next generation.

The scientific novelty of a research is caused by the fact that features of formation of the language personality in student's years, the level of development of foreign language ability and communicative competence of students almost have not been studied. As a rule, researchers pay attention to the formation of proper speech skills in the early childhood (I. N. Gorelov, E.I. Isenina, D. B. Elkonin, etc.) in the middle adolescence (SV Mamaeva, N.S. Beresneva, etc.), in the adulthood (N.D. Golev, I.V. Golubeva, etc.). But the foreign language culture of students often remains outside the scope of research.
The scientific-methodological basis of the research is the theoretical provisions of the methodical, linguistic, psycholinguistic, and psychological sciences, which allow us to give a full description of psychotherapeutic techniques from the linguistic and psychological aspects. The methodological base of the author's work consists of the fundamental research on the theory of speech activity and psycholinguistics (which are represented by the works of AA. Potebnya, V.I. Shakhovskiy, L.S. Vygotsky, N.I. Zhinkina, A.A. Leontyev, etc.), on the theory of cognitive linguistics (G.V. Kolshansky, A.V. Kravchenko, E.S. Cubreacova, J. Lakoff, and others), according to the general theory of the text (N.D. Arutyunova, I.R. Galperin, Yu.S. Stepanova etc.), on onolinguistics (A.A. Zalevskaya, E.I. Isenina, V.B. Kasevich, K.F. Sedov, R.M. Frumkina, A.M. Shakhnarovich, S.N. Tseitlin, and others); intercultural communication (E. Lich, G.E. Kreidlin, M.N. Makeeva, S.T. Ter-Minasova, C. Fergusson and others).

The main methodological principle of the work is the principle of the anthropocentric approach to the language and speech. The leading method of the work relies on observation and experimentation techniques with subsequent analysis of empirical material. A descriptive, comparative method, a statistical method and psycholinguistic techniques were also used during the processing and analysis of the data.

The practical significance of the research is that the data of this work can be used at the lessons on a foreign language to increase the effectiveness of mastering foreign language speech. Moreover the results of the study can be used in special seminars on oral conversational speech, communicative behavior and in the practice of teaching methods of foreign language teaching.

\section{THE PRACTICE CHAPTER}

\section{A. Review of classical techniques of training in foreign languages}

The history of a technique of teaching foreign languages shows many attempts to find the most rational method of teaching foreign languages. However, everybody asks the question: what is the most effective method of training in all types of speech activity in a foreign language?

The teacher of a foreign language needs to have an idea of the existing techniques because it can give an impulse for further creative work, development of the teaching method. The author would like to offer an excursion into methodology and to provide the review of some so-called "classic" methods of teaching foreign languages which have become a reference point for nowadays existing techniques of teaching living languages (these methods were used in the study of Latin).

The most ancient method is natural. It was not different from the method, by which a child is trained in the native language. The foreign language was mastered by imitation of ready samples, by repeated repetition and reproduction of new material. Imitation was the basic and often the only way of reproduction of the acquired knowledge and skills. The grammar was both the purpose and the means of teaching. It would be legitimate to call such method as a grammatical 
imitative-intuitive method [12]. The following method will be discussed in more detail, since it has long been recognized as a standard in Russia. It is possible to master a foreign language quite well. It is the Grammar-transfer method. The purpose of training in foreign languages is development of logical thinking through mastering the language structure according to representatives of this method. The written language was considered as an aberration since the appearance of informal conversation. It has been the basis for training in languages. The grammar of selection, defining of texts and lexicon, was the main object of teaching. The translation was considered from the viewpoint that all languages had the general grammar and words differed only by a visual and sound image. Lexicon was only illustrative material. All foreign words were pledged in word-per-word translations in a nominative form. Students needed to connect these words in the offer.

Language proficiency is mastery of grammar and vocabulary according to this method. The process of improvement is understood as a movement from one grammatical scheme to another. Thus a teacher plans a course on this method and thinks only about grammatical schemes. These schemes, texts, separate sentences are selected by the teacher. Then they are translated from a foreign language into a native language and then from a native language into a foreign language. As for the text, it is usually the so-called artificial text in which the value is practically not given any sense (it is not so important what one will tell, it is important how one will tell). This method has a number of advantages. Firstly, it really allows one to learn grammar at a very high level. Secondly, this method is very good for people with highly developed logical thinking. The main drawback is that the method creates ideal prerequisites for the emergence of the so-called language barrier and a person begins not to speak, but only to combine words by means of certain rules. This way of studying foreign languages prevailed until the end of the 50 s and was practically the only one.

Another method is the Natural method. Psychological and linguistic data of different time were attracted unconsciously during creation of a natural method. The main provisions of this method were derived from observations of the development of speech in the child's native language. Representatives of this method assumed that it is necessary to recreate the natural very characteristic of the child, comprehending elements of the native language.

The main objective of learning of a foreign language method consists in development of oral speech among students according to the principles of a natural. It was achieved by artificial creation of the language environment. The child tries to master foreign speech like the native speech. The creation of this environment is achieved by excluding the native language from teaching. The significance of linguistic phenomena was revealed by means of clarity, context, or definitions. Berlitz and Guén played a positive role in the reform of the teaching foreign languages. However they did not teach the living language, did not provide knowledge of the grammatical system of the language, did not recognize the language of the general educational value.

Another method is the Direct method. The direct method has arisen on the basis of natural. It has received such name because its supporters sought to associate the words of a foreign language and its grammatical forms directly with their value. Psychologists and linguists V. Fiyetor, P. Passi, G. Suit, O. Espersen, B. Eggert and others took part in development of the direct method. They tried to prove this method by the data of linguistics and psychology.

The direct method was a progressive phenomenon in comparison with the methods of the classical school. It gave positive results due to the rationalization of the educational material, the intensive teaching process, the use of visual aids and active teaching methods, and the appeal to the living colloquial language. Interdisciplinary links have become stronger between achievements in the field of pedagogy, linguistics and methodology. The study of languages began to be approached taking the physiological and psychological processes in practice. The shortcomings of the direct method include the following points: identification of ways of studying foreign and native languages; abuse intuition at the expense of conscious study; ignoring the native language, etc

The end of the XX century characterizes the rapid development of political, economic and culture. The development of new different methods of teaching foreign languages appeared. The audio-and-lingual method became a peculiar development of the ideas of the direct method. So in France an audiovisual method was developed.

All the above-mentioned methods of teaching foreign languages are considered as traditional or fundamental (classical) in the methodical literature. All of them came from the grammatical-transfer method and continued for many years.

Now it is the post-communicative phase of development in technique training characterized by cognitive (informative) orientation. This opinion allows us to consider a communicative method in this work within the traditional approach. So let us consider the main characteristics of the communicative method.

In the 1970s, there was not the foreign language mastery, but the "foreign language culture" appeared. It includes the cognitive, educational, developmental and educational aspects. This situation has caused emergence of a question of need of creation of a new methodical system which could provide achievement of this purpose in the most effective and rational way. The communicative method became the new direction.

The aspect of mastering foreign-language culture includes acquaintance and studying not only the language and the grammatical system of the language but also its culture, its interrelation of native culture and a foreign language system. It is the first distinctive feature of this method. The second peculiar feature, as well as main objective of the method, is to teach the person to communicate. According to this technique, 
it is possible to train the person in so-called natural conditions from the point of view of the common sense. So, for example, the teacher's question "What is it?" on a table can be reckoned as natural only with the instruction. The main accent is put on creation of a situation as the systems of relationship between trainees.

A specific feature of the communicative technique is also the use of conditional and speech exercises, which are based on full or partial repetition of remarks of the teacher. The nature of conditional and speech exercises becomes more and more complicated until the statements of the trainees become independent and meaningful.

However, the communicative method does not function to teach the person to communicate.

At the beginning of the 21st century, the human factor of basic paradigmatics has predetermined the most important features of modern linguistics: anthropocentricity, functionality, cognition and integrity. This direction of linguistic research led to the study of the functioning of the language in interaction with the person, with his material and practical and spiritual activity according to the following positions: sociolinguistic, psycholinguistic, cognitive, philosophical. The author agrees with N.F. Alefirenko that if many functions are integrated into the communicative one then some other functions emotional and expressive "can not be represented in the range of communicative function options: there is no element of communication" [16].

The modern communicative method represents a harmonious combination of many ways of teaching foreign languages. Now it is the top of the evolutionary pyramid of various educational methods.

\section{B. Teaching vocabulary in the modern communicative method}

Teaching vocabulary is a very important field; it is not just presenting and introducing new vocabulary to the learners. Learning or knowing words is not filling papers with new words and then memorizing them. Students need to understand the word meaning in the context and how words are used. The teacher can do this with both traditional methods and new, different ways and techniques.

During the presentation of the new vocabulary, special attention should be paid to the peculiarities of the items presented. The teacher needs to make sure that the students have perceived both graphic and phonetic forms of a new word. It is also important to provide the learners with information about the grammatical form of the words. While teaching students vocabulary, the words should be introduced in sentence patterns.

The teachers should use different techniques for presenting the meaning of new items. The teacher should use techniques which are useful, special, and suitable for the learner and his level. To make the learning more interesting and productive, it is recommended to use different modern methods while teaching vocabulary. Today there are many possibilities to enhance vocabulary acquisition with the help of technology. The teacher must be ready to switch from tasks which are unsuccessful in her class, and reorganize the learning process in such way that even the most boring and challenging information is adopted perfectly by students. A teacher must organize memorization and vocabulary practice in such way that even rarely used words are memorized by students so that they can be used when they are required.

The teacher should use her imagination for creating her own song exercises, movie exercises, and presentations which will be suitable for the students. Visual aids, especially movies or videos, are considered one of the most useful and effective ways to teach and to learn English vocabulary. Using videos makes students pay attention to the lesson, arouses their interest in it, and creates a good learning atmosphere during the lesson.

Moreover through movies or videos with sound and picture, learners can enjoy themselves, release stress and have an open mind to learn and perceive words. Besides, learners can benefit a lot from widening communication expressions and phrases.

However several teachers do not take full advantage of them when teaching vocabulary. Some teachers often complain that it would take much time to find the relevant movies or videos for the lessons. Besides, in the videos and movies, there may be some redundant new words, so they have to spend much time explaining them.

There are many internet games based on vocabulary learning, but they should be chosen correctly. And when a teacher uses internet resources, the following principle should be taken in consideration: "Do not harm". While using Internet, one should be prepared, patient, organized, critical and realistic. Technology is just a tool. In terms of getting the kids working together and motivating them, the teacher is most important.

The role of the Internet in teaching vocabulary is doubtless, it helps us as teachers, but one should know how to use it, when to use it, and for whom to use it. PowerPoint presentations can be used in the classroom for teaching vocabulary, grammar, phonetics. It can be used for student projects, for practice and drilling, for games, for reviews, and for tests. Power Point allows teachers to vary their teaching methods and make lessons interesting.

Some scientists consider that PowerPoint is a fun and motivational tool which presents knowledge in an interactive way. Teachers should be moderate in their use of animations, transitions, and other multimedia effects. Overusing PowerPoint can bore learners and reduce the effectiveness of this teaching tool. PowerPoint can be a very helpful tool in the English language classroom, but it is not the solution to every problem.

Instead, one should simply understand when to use Power Point Presentations and how to use them. One should not 
forget that in order to achieve high results in the teaching process, all the tools available should be combined. Power Point, when combined with other methods, can engage students' interest and thus help to make English lessons more memorable. An electronic book can serve as a vocabulary owing to its ability to easily locate a needed word. Electronic books can find a word by simply entering a search keyword. The e-book, created by the teacher, can be used to increase students' interest and motivation in studying foreign languages.

Teachers of the English language can create electronic vocabulary appendixes with visual aids for different traditional books.

The electronic vocabulary can provide vocabulary notes on different topics and thus help students to memorize new words in a better way. Words and word-combinations should have pictures, though not all words can provide pictures, for example for word "to believe", it is too abstract for a proper picture to be located, at least one that would help to convey the meaning to the students and improve their understanding of the word. One has customized an electronic vocabulary, supplemented with pictures, as an appendix to the traditional book "Practical Course". When students see the vivid background of the vocabulary and see the pictures in addition to words and phrases, their levels of motivation and interest are greatly increased.

Therefore they memorize words more quickly, and since their resource is electronic, the students also have the possibility to look through it at home and to use it along with the internet. The internet can be used to send all students the e-book. Power-point presentations, the Internet and electronic vocabularies can serve as the perfect visual aids for introducing new words at the levels of knowledge and comprehension. While teaching Vocabulary, one should combine both traditional and modern methods.

Modern life and a new generation of students demand new ways of teaching, but one should not forget all those old traditional ways of teaching; one should follow the principle of using a variety of activities because if one uses only new or only old methods, students can get bored. One has to combine all the methods one knows, and learn and teach with these. While using multimedia, teachers should take into certain psychological factors: a learner's age, for example. Multimedia can be a helpful tool in teaching foreign languages, but it should not be considered as a solution to all the problems.

The computer itself, without proper pedagogy, psychology, or methodology, does not work. Using multimedia is not simply switching the computer on; it requires more effort to organize the learning process with use of new techniques than without them.

\section{Communicative competence of students as future specialists of an engineering complex}

Communicative competence is one of the basic characteristics of professional competence and professional training of students (future specialists of an engineering complex). Communicative competence is a synthesis of the social, perceptive, reflective, auto psychological, psychological pedagogical competences and related skills. The high level of development of the competence allows communicating effectively in a team of professionals in order to achieve their goals.

Communicative competence is developed through modeling of communicative situations and developing trainings, which help to develop personal and social activity. There are the following structural components of communicative competence: cognitive, regulatory, reflexivestatus and standard components.

The cognitive component includes a high level of professional erudition, knowledge of applied communication strategies, methods of psychological influence, and techniques of rhetoric, polemic, reflective listening and so forth. The regulatory component is the ability to be engaged in dialogue, to persuade, to inspire, to change the communications tactics, to take initiative in any kind of communications.

In psychology, the concept of communicative competence is associated with social and emotional intelligence. "Students with different levels of performance of the competent type of behavior in communication, differ from each other at a statistically significant level of the development of personal qualities, indicating the personal conditioning of their communicative competence.

The highest direct correlations exist between the selfcontrol in communication and a number of characteristics of empathy as personal property. Without specifically organized support of such personality traits as empathy, internality, reflexive, assertiveness, and others, their formation in vocational education takes place only at the secondary level.

Development of communicative competence can be algorithmic, based on the gradual formation of the individual components, education, integrative knowledge, skills and qualities. The leading factor in the development is specifically organized learning environment.

Development of communicative competence can be formation of modern direction communicative competence that is considered as the creation of a psychologist in the educational process of communicative situations that would run mechanisms for the development of the individual. In this case, one deals with the interactive teaching: expansion of joint work of the students, their communicative experience, primarily in the joint venture; the possibility to use not only the consciousness of man, but also his feelings, emotions; involvement in the learning process. Considering the fact that social competence involves skills for effective collaboration and partnership, especially, with regard to the second 
component, it is logical to assume that the social competence and the competence of the quality of the subject's activity includes the ability to prevent, resolve, and manage conflict situations that may arise in the course of interaction with other people.

Thus, we see that the communicative competence acts as a component of social competence. Based on the review of the definitions of social competence and communicative competence, one can imagine how important their role in the professionalization.

\section{Communicative strategy of teachers and students cooperation}

The ideas formulated in the works of LS. Vygotsky, A.N. Leontief, D.B. Elkonina, V.V. Davydov and others are reflected in the approval of cooperation as one of the defining foundations of modern education. Cooperation is a humanistic idea of the joint activity of children and adults, linked by mutual understanding, penetration of each other's spiritual world, collective analysis of the progress and results of this activity. The cooperation strategy is based on the idea of stimulating and guiding the students' cognitive interests.

The problem of educational cooperation (collective, cooperative and group forms of work) is actively developed in Russia and abroad (H.Y. Liimets, V. Doyz, S.G. Yakobson, A.V. Petrovsky, T.A. Matis, L.I. Aidarova, G.A. Tsukerman, A.I. Dontsov) [17].

Cooperation as a joint activity is characterized by:

- $\quad$ spatial and temporal co-presence

- unity of purpose

- $\quad$ organization and management of activities

- $\quad$ separation of functions, operations

- the presence of interpersonal relationships

Main lines of cooperation:

- Teacher-student-teacher.

- Student-student - in pairs (dyads) and in triplets (triads).

- General group interaction of students in the whole teaching collective, for example, the language group.

- The whole class.

- Teacher - teaching staff.

General characteristic of the influence of cooperation:

- Difficult cogitative tasks are more successfully solved.

- New material is better acquired.

- Level of communicative abilities increases.

- Intragroup cooperation increases its efficiency not less than by $10 \%$ in comparison with individual work by the scheme "the teacher-the pupil".

- The triad is more productive than a dyad in comparison with all-group $(7-12$ people $)$ interaction, but the collectivizing advantages of a large group cannot be overestimated.
The principle of collective activity is characterized in three plans:

- the installation of students for collective creativity,

- the active participation of each student in the task,

- the choice by each student of a person-significant subject of activity in the sense of knowledge of the means of designating this object, ways of expressing it and its preferences, which ensures the individualization of the learning process.

One recognizes the existence of various methods in teaching foreign languages, but it is possible to think that the communicative method is the dominant one for us.

Principles of constructing the content of communication:

- Speech Direction

- Individualization

- Functionality

- Situation

- Novelty

- Personal orientation of communication

- Collective interaction

- Modeling

The method will be effective if the styles of pedagogical communication are distinguished:

- Communication on the basis of enthusiasm for joint creative activity;

- Friendly location,

- Communication - distance,

- Communication - intimidation,

- Communication - flirtation.

Heart-to-heart talk is practically trouble-free. The student is more interesting to talk about pressing problems or about some amazing event instead of a traditional conversation about the weather. The main goal is to start a conversation with a special expression creating an atmosphere of "heart to heart talking":

-What wonderful weather we are having today!

- Just fancy! On my way here, I met a homeless puppy. It looked so sick and miserable. I couldn't help stopping and feeding him.

Warm-up. Exercise from the psychological training "listen to silence". The teacher and students sit in a circle; they close their eyes and listen for a minute to the sounds around them. At the end of the minute, everyone opens their eyes and tells what they heard.

Drawing. It can be attributed to five-minute warm-ups. However, it is possible to build on it the whole lesson, especially if it is a lesson in oral speech. The teacher enters the classroom with a worried face and reports that one of the students is summoned to the director. While the student is absent, the team discusses and assumes the reason for the student's call. The bottom line is that the intrigue allows 
keeping the group in suspense and for a while to forget about the language because such important matter is being clarified.

A special place in the dialogical speech is assigned to the use of role play. Two options are possible when conducting a role-playing game:

- the student is offered the role of another person

- the student depicts himself as one who has fallen into a certain situation.

In the second year, students are offered an excerpt of S. Maugham's story about a friend. The protagonist Barton, a prosperous businessman, does not care a single bit about the problems and needs of those who fail in this life. He does not hesitate a minute. He sends a man to his doom only because he ignored his requests to take him to work, later he remembered it. The teachers prepare a role-playing game called "Court" where they accuse Barton of deliberately killing a person. The roles were divided: the judge, the prosecution, the defense, the accused Barton, the witnesses. Other students played the role of the jury who needed to render the verdict "guilty" or "not guilty". The purpose of this lesson was also the creation in the classroom of the atmosphere of the surrounding world in order to use lexicon.

Making up a story stimulates the student to use and involve all elements of the language, develops the fluency of speech, the ability to reveal this topic, the ability to improvise. For example, one can offer: the story of the students about the plot of the scanned film and the recommendation to see it; compilation of a detailed verbal portrait of his classmate (topic "Characters, feelings and emotions of people"). It is interesting to compile stories. For example, the topic "School education in Russia and abroad". The group is divided into two teams, team representatives go to the table one by one and take cards. The person who took the card should speak on the given topic without preparation in a minute, starting with the one written in the card. The person, who is able to withstand this condition, receives a penalty point.

Problem tasks. Their goal is to teach them to express their opinions briefly, to make proposals, to request information, to compare, agree or disprove the statements of other participants in the event.

Discussion can be attributed to the most productive types of communication activities. Personally, the author took such topics for discussion as: the degree of prestige of professions in modern society; the importance of a limited number of items that need to be taken to the expedition; the degree of usefulness of the objects that need to be built in one's city. Training communication through cooperation allows one to overcome the greatest difficulty. It is a speech barrier (intention). The student's speech intention is blocked or becomes unnatural.

For a number of years, the author's students had the opportunity to communicate. Specialists of many countries work in Tyumen and they participate in the educational process as representatives of other cultures. Environmental problems of the planet were discussed together during the study of the topic "Earth is our common home". And representatives of countries such as Denmark, England, France and Indonesia told what was being done to conserve natural resources in their countries. There was an active exchange of recipes for culinary art of Russian and Danish cuisine during the study of the topic "Food". The students went home with recipes for dessert dishes, and there was Dane Borg Matheson with a jar of cowberry jam, which reminded him of his mother's jam. Then the process of acquaintance and adaptation was over and speakers actively participated in the formation of pronunciation, lexical, grammatical skills of students. They demonstrated their country's profound knowledge, political, economic, cultural points of view. Poems of Russian poets were read by everyone who wanted to share family traditions and ways of life; an exchange of photos took place. Communication continues now. They called such meetings as "A cup of tea in English".

Thus, the author considers the pedagogy of cooperation as humanistic in its philosophical basis. The author dwells on general pedagogy in terms of application and she considers integrated pedagogy as the main development factor. It is oriented to the harmonious personal development of each student, to education and upbringing. By the nature, the content is general, penetrating. The author especially emphasizes the importance of the possibilities for organizing academic, club, individual, group, differentiated work, the ability of the small group system to manage the learning process, and problem-searching, creative, dialogical, and gaming methods. The application of these methods, methods and the quality of the students' training testify to the effectiveness of teaching in the cooperation and development of the communicative activity of students in the classroom.

\section{CONCLUSION}

The author concluded that after the analysis of various teaching methods of foreign languages, their appearance is conditioned by the needs of society. Knowledge of grammar was sufficient in the XVII-XVIII centuries. Therefore, a grammatical-translation method arose. The purpose of it was to master the structure of the language. As for the texts, they were a set of unrelated sentences in order not to distract the attention of the students from the content.

In the 19th century, the development of the economic, political relations between the countries has defined the purpose of a learning the foreign language - mastering oral speech. It has led to emergence of a direct method of training in the foreign languages. The direct method primary consisted in acquisition of the foreign language for a long period of time. Then it changed into indirect methods, audio-lingual and audiovisual methods.

The modern development of the methodology of teaching a foreign language is due to the development of a competent approach which orient towards a wider use of the possibilities of the theory of speech activity. The author especially emphasizes the importance of the possibilities for organizing 
academic, club, individual, group, differentiated work, the ability of the small group system to manage the learning process, and problem-searching, creative, dialogical, and gaming methods. The application of pedagogical methods and the quality of the students training testify to the effectiveness of teaching in the cooperation and development of the communicative activity.

\section{References}

[1] d'Antoine de Saint-Exupéry, Le Petit Prince, Paris, Folio, 2006, 336 p.

[2] B.C Kukushin, Theory and methods of teaching, Rostov na Donu, Feniks, 2005, 474 p. (in Russian).

[3] N.F. Alefirenko, Modern problems of the science of language, M.: Flinta, 2005, 412 p. (in Russian).

[4] A.A. Isakova, "Retrospective Analysis of Communicative Competence Development," Integration of education, vol. 21, No.1(86), pp. 46-53, January-March 2017.

[5] B.Ja. Sharifullin, "General characteristics of the speech situation in the Russian city of the beginning of the XXI century," Ecology of language and communicative practice, No. 1, pp. 67-85, 2014. (in Russian).
[6] H. Widdowson Aspects of language teaching, Oxford: Oxford University Press, 1988, $214 \mathrm{p}$

[7] Ya.I. Berdichevsky, Old book. Bibliophile Almanac, No. 30, M., 2006, 224 p. (in Russian).

[8] B. M. Gasparov, Language, memory, image. Linguistics of language existence., M.: New literary review, 1996, 352 p. (in Russian).

[9] G. Quirk, Developing paragraph organization skills at the college level, Cambridge: CUP, 2001, 95 p.

[10] A.A. Isakova, "Communication strategies of the Tyumen region space," Mezhdunarodnyj nauchno-issledovatel'skij zhurnal, 2016, № 5-2 (47), P. 39-41

[11] N.I. Gez, M.V. Ljahovickij, A.A. Miroljubov, Methods of teaching foreign languages in secondary school, M.: High school, 1982, 373 p. (in Russian).

[12] I.V. Rahmanov, N.I. Gez, I.A Zimnjaja, S.K Folomkina, A.Ja. Shajkevich, The main directions in the teaching of foreign languages in the XIX-XX, in 3 parts, M.: Pedagogika, 1972, 320 p. (in Russian). 